\title{
What we know about 2019-nCoV in Iran in the early stage?
}

\author{
Milad Dodangeh ${ }^{1}$ (1) Masoud Dodangeh $^{2} \cdot$ Mohammadamin Joulani $^{1} \cdot$ \\ Azinmehr Elahian Boroujeni ${ }^{1}$
}

Received: 13 March 2020/Accepted: 28 April 2020/Published online: 22 May 2020

(C) Indian Virological Society 2020

\begin{abstract}
On 10 January 2020, a new coronavirus causing a pneumonia outbreak spread rapidly in all of the World. On 19 February 2020, the first official announcement of death from 2019-Nov was made in Iran. As of 7 March 2020, there were 101,927 confirmed cases of Covid-19 infection, including 3486 deaths, reported in the World. In the eastern and Mediterranean region Iran with 4747 confirmed cases of Covid-19 infection and 124 deaths, is in the critical stage. Therefore, there is a matter of urgency combating this new virus and stopping the epidemic. Here, we focus on symptoms and the development of fast diagnosis methods, as well as potential management to prevent or treat the Covid-19 infection.
\end{abstract}

Keywords Coronavirus · Covid-19 · 2019-nCov · Iran

\section{Introduction}

One of the major causes of morbidity and mortality worldwide is viruses $[4,7]$. Coronaviruses (CoVs) belong to the family Coronaviridae in the order Nidovirales and they are enveloped, positive-sense, single-stranded RNA viruses. They have the zoonotic origin and they are distributed broadly among humans and other animals like mammals and birds, which cause respiratory, hepatic, enteric, and neurologic diseases [13]. Two fatal

Milad Dodangeh

dodangeh.m@iums.ac.ir; milad_dodangeh@yahoo.com

1 Student Research Committee (SRC), Faculty of Medicine, Iran University of Medical Sciences (IUMS), Shahid Hemmat Highway, Tehran 1449614535, Iran

2 Tehran, Iran coronaviruses emerged periodically in the world in 2002 and 2012. The first one was severe acute respiratory syndrome coronavirus (SARSCoV) and the second one was Middle East respiratory syndrome coronavirus (MERSCoV) [12].On 10 January 2020, the World Health Organization (WHO) identified the unknown pathogen as a novel coronavirus denoted as Covid-19 or 2019-nCoV. On 19 February the first case was reported in Iran [14]. The patient was found in the Kamkar-Arabnia Hospital of Qom, a city located near Tehran [2]. Currently, Tehran, Qom, and Mazandaran have the highest number of patients in Iran and are in critical condition. However, no city has been quarantined in Iran and this has led to an increasing number of patients every day. As of 7 March 2020, there were 101,927 confirmed cases of Covid-19 infection, including 3486 deaths, reported in all of the world. In the eastern and Mediterranean region, Iran with 4747 confirmed cases of Covid-19 infection and 124 deaths, is in the critical stage [15].

\section{How did Covid-19 start in Iran?}

Iranian authorities have put forward two theories for the start of the 2019-nCoV in Iran. The first theory was an Iranian airline flying many times to China at the Wuhan 2019-nCoV outbreak. The second theory was the return of an Iranian businessman who had returned from china to Qom with several flights [2]. Neither of these two theories has been substantiated at this time and should be further investigated. 


\section{Symptoms of Iranian Covid-19 patients}

Due to the current epidemiological survey, most individuals had a history of close contact with the 2019-nCoV infected patient. The incubation period is commonly 3-7 days [16]. On January 2, 2020, Huang et al. [5], first reported clinical features of 41 patients confirmed to be infected with 2019-nCoV. The characteristics of Covid-19 infected patients in hospitals of Tehran, Iran are approximately the same as all of the world. New symptoms previously not known yet in the world has not seen in Iranian patient until now. With the rise of cases worldwide, the symptoms of the disease have been better characterized. The symptoms of 2019-nCoV infection are nonspecific. Fever, cough, dyspnea, myalgia or fatigue, sputum production, headache, hemoptysis, and diarrhea are initial Covid-19 symptoms. The most common symptoms are onset fever, generalized weakness, and dry cough. Some patients have headache and/or myalgia, but upper respiratory symptoms such as runny nose are rare [16]. Some cases have Diarrhea, which had been reported $10.6 \%$ in SARS and up to $30 \%$ in MERS [1]. Most of the patients have shortness of breath. If the disease could not be controlled, they might develop acute respiratory distress syndrome (ARDS), followed by septic shock, refractory metabolic acidosis and coagulation dysfunction [16].

\section{Covid-19 diagnosis by laboratory testing}

In most cases total white blood cells, lymphocyte, and platelet are lower than the average with extended activated thromboplastin time, increased C-reactive protein and muscle enzyme level. In the early days of the disease, these symptoms are not detectable. In severe disease, the D-dimer level is higher and lymphocyte decrease progressively and the cytokine storm such as IL1B, IL1RA, IL7, IL8 can be associated with disease severity [5, 1]. On chest CT scans, the multifocal ground glass changes are typical of viral pneumonia. If the disease continued to develop and in the bilateral multiple lobular and subsegmental areas of consolidation would be found on chest CT scan. The lungs of elderly patients showed more diffuse and extensive imaging than those of the younger patients $[5,1]$.

In Iran, the government has stated that they can perform three coronary tests per day, which are critical to screening for coronavirus. These tests are appropriate in the early days of the disease. But as the number of patients progresses, more tests will need to be done [2].

\section{Vaccines and treatments}

In vulnerable populations that are vulnerable to severe damage, when Vaccines exposed to a particular pathogen of interest, they can protect against disease and infection. Several efforts to develop Covid-19 vaccines are underway, but the WHO and scientists estimate it will take one to two years to be available and ready to use [10]. There are already a number of vaccine candidates being developed but most are still in the preclinical testing stage.

Although anti-inflammatory and antiviral treatments have been employed present, at present in all of the world and Iran, most treatment is symptomatic and supportive. For complicated patients, supportive treatment has included continuous renal replacement therapy (CRRT), invasive mechanical ventilation, and even extracorporeal membrane oxygenation (ECMO).

There aren't any specific antiviral drugs that confirmed effective. Remdesivir [3], Ritonavir [9] and Baricitinib [11] suggested as a potential drug for the Covid-19 treatment. A new study conducted by the "front-line" medical providers combating 2019-nCoV in China indicated that systemic corticosteroid treatment didn't show remarkable benefit [8]. According to the searches we made at the Iranian Registry of Clinical Trial (IRCT) [6], we found that no studies have been conducted in Iran about 2019-nCoV so far.

On March 1, 2020, Baqiyatallah Medical Sciences University (BMSU) announce that they are developing drugs and a vaccine for Covid-19. Three research groups in BMSU were working on treatments for Covid-19, one of the teams had already come up with a drug that could be used to cure the illness and one of the drugs has passed laboratory tests. Iranian researchers in BMSU also were working on a human genetic material Covid-19 vaccine. They hope that the human genetic material Covid-19 vaccine would be developed within less than 12 months to help all of the world countries to prevent the spread of the Covid-19 infection [2].

Although trials of vaccines and antivirals are underway, treatment is mainly supportive and symptomatic. It is important to inform the medical staff that they are at risk and they should use protective measures. Healthcare providers and the government should follow subsequent reports as the situation will likely change rapidly and benefit from the results of new research.

\section{References}

1. Chan JF-W, Yuan S, Kok K-H, To KK-W, Chu H, Yang J, et al. A familial cluster of pneumonia associated with the 2019 novel 
coronavirus indicating person-to-person transmission: a study of a family cluster. The Lancet. 2020. https://doi.org/10.1016/ S0140-6736(20)30154-9.

2. Deputy of Health. Covid-19 Bulletin (Version 1). Ministry of Health and Medical. 2020. https://health.behdasht.gov.ir/uploads/ Bultan_Covid19_1.pdf.

3. Holshue ML, DeBolt C, Lindquist S, Lofy KH, Wiesman J, Bruce $\mathrm{H}$, et al. First Case of 2019 Novel Coronavirus in the United States. N Engl J Med. 2020. https://doi.org/10.1056/ NEJMoa2001191.

4. Howard CR, Fletcher NF. Emerging virus diseases: can we ever expect the unexpected? Emerg Microb Infect. 2012;1:1-9. https:// doi.org/10.1038/emi.2012.47.

5. Huang C, Wang Y, Li X, Ren L, Zhao J, Hu Y, et al. Clinical features of patients infected with 2019 novel coronavirus in Wuhan, China. Lancet. 2020. https://doi.org/10.1016/S01406736(20)30183-5.

6. Iranian Registry of Clinical Trials. 2020. https://www.IRCT.ir.

7. James SL, Abate D, Abate KH, Abay SM, Abbafati C, Abbasi N, et al. Global, regional, and national incidence, prevalence, and years lived with disability for 354 diseases and injuries for 195 countries and territories, 1990-2017: a systematic analysis for the Global Burden of Disease Study 2017. The Lancet. 2018;392:1789-858. 6736(18)32279-7.

8. Kui L, Fang Y-Y, Deng Y, Liu W, Wang M-F, Ma J-P, et al. Clinical characteristics of novel coronavirus cases in tertiary hospitals in Hubei Province. Chin Med J (Engl). 2020. https://doi. org/10.1097/CM9.0000000000000744.

9. Liu. Ying. A randomized, controlled open-label trial to evaluate the efficacy and safety of lopinavir-ritonavir in hospitalized patients with novel coronavirus pneumonia (COVID-19). Wuhan Jinyintan Hospital (Wuhan Infectious Diseases Hospital). 2020. https://www.chictr.org.cn/showprojen.aspx?proj=48684.

10. Ministry of Health and Medical Education. WHO says vaccines against novel coronavirus 18 months away, pushes global research. 2020. https://behdasht.gov.ir/.

11. Richardson P, Griffin I, Tucker C, Smith D, Oechsle O, Phelan A, et al. Baricitinib as potential treatment for 2019-nCoV acute respiratory disease. The Lancet. 2020. https://doi.org/10.1016/ S0140-6736(20)30304-4.

12. Su S, Wong G, Shi W, Liu J, Lai ACK, Zhou J, et al. Epidemiology, genetic recombination, and pathogenesis of coronaviruses. Trends Microbiol. 2016;24:490-502. https://doi.org/10. 1016/j.tim.2016.03.003.

13. Weiss SR, Leibowitz JL. Coronavirus pathogenesis. Adv Virus Res. 2011;81:85-164. https://doi.org/10.1016/b978-0-12-3858856.00009-2.

14. World Health Organization. Coronavirus disease 2019 (COVID19) Situation Report-31. 2020. https://www.who.int/emergencies/ diseases/novel-coronavirus-2019/situation-reports.

15. World Health Organization. Coronavirus disease 2019 (COVID19) Situation Report-47. 2020. https://www.who.int/emergencies/ diseases/novel-coronavirus-2019/situation-reports.

16. World Health Organization. Diagnosis and treatment of new coronavirus pneumonia (version 5). 2020. https://www.who.int/ docs/default-source/coronaviruse/who-china-joint-mission-oncovid-19-final-report.pdf.

Publisher's Note Springer Nature remains neutral with regard to jurisdictional claims in published maps and institutional affiliations. 